\title{
Teoria das mediações sociais: refinamento ou obsolescência?
}

\section{Ana Maria Dantas de Maio}

\section{Resumo}

0 artigo propõe um mergulho nas origens e

concepções recentes da teoria das mediações sociais, proporcionando reflexões a respeito de sua aplicabilidade. Aponta fragilidades metodológicas e resgata críticas conceituais fundamentadas no afastamento da teoria do campo da comunicação. Relaciona pesquisas atuais sobre as mediações ao conceito de midiatização, tendência seguida por pesquisadores brasileiros e estrangeiros. Por meio da pesquisa bibliográfica, conclui que a teoria está em permanente construção e, potencialmente, consegue responder a alguns questionamentos comunicacionais.

\section{Palavras-Chave}

Mediações. Midiatização. Meios de comunicação. Bios midiático.
Ana Maria Dantas de Maio I anamaio@uol.com.br Doutora em Comunicação Social pela Universidade Metodista de São Paulo - UMESP, Brasil. Jornalista do Núcleo de Comunicação Organizacional da Embrapa Pantanal.

\section{Introdução}

0 termo mediação segue controverso no âmbito da pesquisa em comunicação, ora exprimindo o uso de meios técnicos na interação entre sujeitos - em uma perspectiva bastante simplista -, ora representando o processo de negociação de significados que envolve a recepção de mensagens, baseado em elementos culturais das sociedades onde ocorre. 0 objetivo deste artigo é promover uma discussão epistemológica, começando pelo resgate da origem da teoria das mediações sociais, promovendo uma atualização conceitual e problematizando algumas questões apresentadas por autores clássicos e contemporâneos, na tentativa de contribuir para a luminosidade do tema. Também faz parte do escopo deste estudo inserir o conceito de mediação nas pesquisas sobre midiatização, fenômeno que caracteriza a sociedade hodierna.

A proposta está longe de esgotar a discussão sobre a polêmica teoria das mediações sociais, a qual merece aprofundamentos constantes. Em função do limite de espaço, nem todos os autores citados terão suas obras tratadas com o detalhamento que merecem ${ }^{1}$. 
Isto posto, o percurso se inicia por uma breve análise semântica do termo mediação, saltando, em seguida, para as origens da então Teoria da Mediação Social (no singular), com o espanhol Manuel Martín Serrano; revisita os estudos comparativos sobre mediação e reflexo elaborados por Raymond Williams, dos Estudos Culturais Ingleses; explora as ideias de Jesús MartínBarbero, bem como as críticas ao pensamento barberiano e de alguns de seus seguidores; até chegar a um cenário mais atual, quando esse conhecimento passa a ser atrelado aos estudos sobre midiatização. A pesquisa bibliográfica fundamenta 0 trajeto metodológico deste estudo.

\section{Uma breve exploração semântica sobre mediação}

0 significado do termo mediação pode variar de acordo com o contexto do que se pretende classificar como mediado. 0 entendimento mais técnico e simplista está relacionado ao sentido de "intermediação", ou seja, um instrumento que se interpõe entre sujeitos interlocutores. De acordo com a definição de Thompson (2008, p. 78-79),

as interações mediadas implicam o uso de um meio técnico (papel, fios elétricos, ondas eletromagnéticas, etc.) que possibilitam a transmissão de informação e conteúdo simbólico para indivíduos situados remotamente no espaço, no tempo, ou em ambos. [...] Os participantes não compartilham o mesmo referencial de espaço e de tempo e não podem presumir que os outros entenderão expressões denotativas.

Essa noção de "intermediação", de algo que aproxima partes separadas, parece estar impregnada no termo mediação, dificultando a construção do conceito dentro de outra perspectiva, mais complexa, que passa a envolver elementos que circundam o processo comunicacional, especialmente na instância da recepção. Neste caso, o sentido é diverso e as complicações começam pelas dificuldades de tradução.

Pesquisadora do Reino Unido, Livingstone (2009) constata imprecisões ao consultar colegas de idiomas esloveno, polonês, tibetano, islandês, português, búlgaro, estoniano, francês e alemão e verificar que os sentidos para "mediation" não coincidem nessas distintas línguas.

Os significados de "mediation" em inglês e "mediação" em português divergem. De acordo com Livingstone (2009, p. 4, tradução nossa, grifo da autora), "em português, mediação é usado como um termo acadêmico para a negociação dos significados dos meios entre produtores e consumidores, apesar de este não estar no uso rotineiro nem ser nosso uso do termo em inglês".

Há ainda o conceito foneticamente semelhante de “midiação", proposto por Thompson (2011), que vem do original em língua inglesa "mediazation" 
e é utilizado no contexto social e histórico da transmissão de formas simbólicas da cultura moderna. 0 processo que ele descreve como "midiação" trata da "proliferação rápida de instituições e meios de comunicação de massa e 0 crescimento de redes de transmissão através das quais formas simbólicas mercantilizadas se tornaram acessíveis a um grupo cada vez maior de receptores" (THOMPSON, 2011, p. 21). Difere, portanto, do sentido de mediação adotado pelos estudos latino-americanos.

Considerado o precursor da teoria da mediação social, o espanhol Manuel Martin Serrano (1976, p. 180, tradução nossa) define mediação como "a atividade de controle social que impõe limites ao que poderia ser dito, e às maneiras de dizêlo, por meio de um sistema de ordem". Ele teria inspirado outro espanhol, Jesús Martín-Barbero², a aprofundar os estudos sobre o tema na América Latina. Na década de 1980, Martín-Barbero preconizava que a pesquisa em comunicação deveria migrar seu foco dos meios de comunicação para as mediações.

Eu, desde 0 começo, por intuição, me opus à visão hegemônica, norte-americana, de estudar os efeitos dos meios. Eu não negava a importância dos meios, mas dizia que era impossível entender a importância, a influência nas pessoas, se não estudássemos como as pessoas se relacionavam com os meios. 0 que eu comecei a chamar de mediações eram aqueles espaços, aquelas formas de comunicação que estavam entre a pessoa que ouvia 0 rádio e 0 que era dito no rádio. [...] Mediação significava que entre estímulo e resposta há um espesso espaço de crenças, costumes, sonhos, medos, tudo 0 que configura a cultura cotidiana. (MARTíN-BARBER0, 2000, p. 154).

A controversa teoria das mediações sociais pode ajudar a compreender o significado dos termos mediação e mediações. Para tanto, é recomendável retroceder no tempo para conhecer como ocorreu a construção desse conhecimento.

\section{Teoria das mediações sociais: origens e atualizações}

Na América Latina, o termo "mediação" começa a obter sua configuração atual entre 0 final da década de 1970 e início da de 1980, quando autores espanhóis se debruçam sobre 0 tema e quando o galês Raymond Williams o problematiza, relacionando-o à teoria dos reflexos, conforme será visto adiante. A teoria da mediação social (no singular) foi proposta por Manuel Martin Serrano nessa época3. "Do ponto de vista formal, a mediação equivale ao sistema de regras e de operações aplicadas a qualquer conjunto de atos, ou de coisas pertencentes a planos heterogêneos da realidade, para introduzir uma ordem" (MARTIN SERRANO, 1976, p. 179, tradução nossa).

Nascido na Espanha, Martín-Barbero vive na Colômbia desde 1963 e sua obra tem grande capilaridade entre pesquisadores brasileiros.

A partir do momento em que outros teóricos latino-americanos se apropriam dos primeiros estudos de Martin Serrano, eles passam a denominá-la de teoria das mediações sociais, no plural. 
Considerado um dos estudiosos que ajudaram a quebrar paradigmas na pesquisa em comunicação na América Latina, Martin Serrano defende que as investigações deveriam privilegiar a criatividade e 0 compromisso com a ética, o que confrontava os interesses autoritaristas que vigoravam na região naquele período e rompia com o modelo funcionalista de investigação importado dos Estados Unidos (MALDONAD0, 2008). A linha de pensamento do espanhol considera que a análise das mediações está relacionada ao controle social e, em consequência, a questões envolvendo o poder.

Ao desenvolver seu estudo para tentar dirimir "uma confusão entre a televisão (com minúscula) como objeto tecnológico e a Televisão (com maiúscula) como instituição social mediadora", Martin Serrano (2010, p. 5) acaba por construir as bases da teoria da mediação social. 0 pesquisador defende que 0 controle social exercido por essa mídia ocorre menos em função da diversidade de conteúdo que ela oferece à audiência e mais pela restrição de códigos de interpretação transmitidos por meio das mensagens. A noção de código pode tanto ser concebida em sua versão mais simplificada - a ideia de um sistema codificante -, quanto estar associada a uma tomada de posição em relação aos acontecimentos, aderindo, assim, ao conceito de ideologia.
"De acordo com essa hipótese, ao Mediador será possível controlar a visão de mundo oferecida à audiência na televisão, sem necessidade de declarar explicitamente juízos de valor" (MARTIN SERRANO, 2010, p. 6, tradução nossa). Pesquisa empírica desenvolvida pelo autor, aplicando o modelo mosaico de análise dos atributos ideológicos em personagens de televisão, revela que, de uma combinação teoricamente possível de 559.871 subconjuntos de estereótipos narrativos, a televisão oferecia à audiência apenas 29 subconjuntos ${ }^{4}$, limitando, dessa maneira, 0 acesso à amplitude de visões de mundo.

De certo modo, ao impor uma forma singular de apresentar a realidade, a instância mediadora introduz um efetivo sistema de controle sobre essa realidade. Em outras palavras, enquanto instituição mediadora, a televisão "permite incluir a interpretação que se quer induzir como um componente da informação" (MARTIN SERRANO, 2007, p. 16, tradução nossa), ou seja, ela instaura o modo de conceber 0 mundo que lhe convém. $\mathrm{Na}$ prática, ao consumir um conteúdo midiático, frequentar um determinado espaço físico ou selecionar um prato em um cardápio, essa distinção entre a mensagem e as regras de interpretação não se evidencia. 
Em outro estudo, Martin Serrano (2007) amplia sua preocupação com a pseudoconstrução da realidade assumida pela mídia em função de regras do mercado. Ele questiona a legitimidade da relação produzida pela mídia entre objetos naturais e objetos fabricados.

\begin{abstract}
A economia de mercado prossegue com sua inevitável missão de utilizar para um uso econômico todos os territórios e recursos existentes. $A$ transformação dos bens de livre disposição em mercadorias se corresponde, a nível das mentalidades, com a identificação entre 0 fabricado e o natural. A água é engarrafada e vendida como "pura". Os espaços inexplorados são urbanizados e promovidos como "virgens". Neste livro [La Mediación Social] se mostra que, pela primeira vez na história, os objetos (artificiais) ocupam as representações, o lugar das coisas (naturais). A forma como o mercado vem vinculando a natureza com a produção supõe uma reconstrução da imagem do mundo. (MARTIN SERRAN0, 2007, p. 20, tradução nossa, grifos do autor).
\end{abstract}

De acordo com Mate (1984), que aprofundou os estudos sobre o livro La Mediación Social, identifica-se um processo de mediação quando os objetos materiais ou imateriais são associados a determinados objetivos por meio de um processo de interpretação da realidade, que direciona comportamentos e ações. "Portanto, a mediação, na comunicação, não se manifesta tanto no nível dos conteúdos explícitos, como no nível da organização dos relatos; concretamente, a mediação opera na seleção de dados de referência e na conexão entre os dados de referência" (MATE, 1984, p. 75, tradução nossa).
As mediações não são impostas: elas instalam-se a partir de relações ideológicas compartilhadas entre indivíduos, grupos, organizações ou sociedades, articulando os modos como a realidade será interpretada pelos sujeitos. Não obstante, elas não operam de maneira isolada, o que interfere diretamente no processo de construção do real. Ao mesmo tempo em que 0 sujeito possa estar sob orientação da mediação dos meios de comunicação (massivos ou não), ele se submete a outras instâncias mediadoras, como sua própria cultura, sua experiência cognitiva, as noções espaçotemporais que vivencia, a linguagem através da qual se comunica, entre muitas outras. 0 que se observa, no entanto, é que essas outras dimensões têm sido elaboradas, cada vez mais, a partir de conteúdos (e códigos) disponibilizados midiaticamente. Essa relação configura-se como embrionária do processo de midiatização que será abordado posteriormente.

Talvez em função dessas relações complexas, Martin Serrano tenha sido um dos primeiros estudiosos a observar que a tentativa de controlar as mediações torna-se sedutora. "Controlar a forma de mediar é aplicar ao conteúdo da realidade 0 modelo de ordem e 0 tipo de significações que posteriormente serão utilizados pelo destinatário da informação para compreender o presente, prever o futuro e, portanto, para atuar" (MARTIN SERRANO, 1976, p. 181). Por vezes, esse controle é exercido de modo sutil, como na escolha de símbolos que 
serão utilizados na comunicação a partir de um repertório disponível.

A abordagem de Martin Serrano, inovadora para a época, mostra-se pertinente e atual. 0 autor consegue, ainda que de forma introdutória, descolar a noção de mediação da ideia de intermediação e constrói o alicerce teórico que fundamenta a perspectiva latino-americana da teoria das mediações, baseada na sociologia da cultura. Ademais, os estudos do espanhol abrem caminho para desvincular o conceito de mediação dos meios de comunicação, apesar de sua pesquisa empírica ter sido conduzida junto à televisão. 0s códigos mediadores que direcionam leituras e interpretações estão presentes em outras instâncias e podem ser identificados e compreendidos à luz da teoria apresentada.

Raymond Williams, do Centro de Estudos Culturais Contemporâneos, na Universidade de Birmingham (Inglaterra), também foi pioneiro no estudo do conceito de mediação, associando-o às teorias do reflexo. Williams pesquisava as relações entre arte e sociedade ao verificar que 0 termo "mediação" seria atraente para definir possíveis alterações nas produções culturais em relação ao mundo real. No contexto estudado, a arte refletia a realidade - eventuais não conformidades com o mundo real eram vistas como distorções. Essa visão positivista era contestada pelo autor.

Ainda segundo Williams (1979, p. 101), "não devemos esperar encontrar (ou encontrar sempre) realidades sociais 'refletidas' diretamente na arte, já que estas (sempre ou com frequência) passam através de um processo de 'mediação', no qual seu conteúdo original é modificado". Essa modificação envolveria disfarces ou deformações, em uma visão negativa do conceito. Já em uma visão positiva, fundamentada pela Escola de Frankfurt, a mediação estaria "no objeto em si, não em alguma coisa entre o objeto e aquilo a que é levado" (WILLIAMS, 1979, p. 101).

Apesar da tentativa, o teórico relatou muita dificuldade em desvincular a ideia de mediação da concepção dualista que envolveria a relação entre partes separadas. Diz ele que "é praticamente impossível manter a metáfora da 'mediação' (Vermittlung) sem certo senso de áreas separadas e preexistentes, ou ordens de realidade, entre as quais o processo de mediação ocorre, quer de maneira independente, quer determinado pelas suas naturezas anteriores" (WILLIAMS, 1979, p. 102). Acabou abandonando o conceito.

Considerados na contemporaneidade uma forma importante de mediação, os meios de comunicação tiveram sua hegemonia questionada pelo pesquisador espanhol-colombiano Martín-Barbero, autor do clássico Dos meios às mediações.

Segundo Martino (2009, p. 179, grifos do autor),

0 livro propõe um deslocamento dos estudos de Comunicação: no lugar de se preocupar com os meios e suas condições específicas de produção ou mensagem, era preciso pensar nas mediações, nos processos culturais, sociais e econômicos que enquadravam tanto a produção 
quanto a recepção das mensagens da mídia. [...] Pode-se entender por mediações as estruturas de construção de sentido às quais o receptor está vinculado. A história pessoal, a cultura de seu grupo, suas relações sociais imediatas, sua capacidade cognitiva são mediações, mas também interferem no processo sua maneira de assistir televisão, sua relação com os meios e com as mensagens veiculadas.

As investigações sobre mediações, concebidas naquela ocasião como matriz epistemológica por Martín-Barbero, se contrapõem ao modelo funcionalista norte-americano que privilegiava os estudos dos meios de comunicação e seus efeitos. "Nesse sentido, algo que marca o pensamento de Martín-Barbero é a centralidade do serhumano - inserido em seu lugar social e marcado por vivências e mediações - nos estudos da comunicação" (BARROS, 2009, p. 90).

Mais recentemente, 0 investigador opta por rever sua proposição inicial e desloca suas pesquisas das mediações culturais da comunicação para as mediações comunicativas da cultura. Essa migração acontece porque MartínBarbero percebe a força com que os meios de comunicação incidem sobre a sociabilidade. Se até então 0 colombiano vislumbrava 0 protagonismo das condições de recepção das mensagens, nessa nova visão MartínBarbero estaria contemplando uma espécie de midiatização da cultura (BARROS, 2012) reconhecendo a inter-relação entre as noções de mediação e midiatização na contemporaneidade. 0 ambiente que acolhe essa mudança paradigmática é denominado, apropriadamente, de "entorno tecnocomunicativo" por MartínBarbero (2009b).

0 autor constata que, mesmo nos países latinos, as pessoas estão cada vez mais isoladas e dedicando seu tempo aos meios.

De alguma maneira, nesse momento aceito que
muda o lugar a partir do qual estava olhando.
Olhava a partir da nossa cotidianidade comu-
nicativa latino-americana, rica, festiva, e a con-
trapunha à solidão dos norte-americanos [...].
Era preciso assumir não a prioridade dos meios,
mas sim que "o comunicativo está se transfor-
mando em protagonista de uma maneira muito
mais forte". (MARTíN-BARBER0, 2009a, p. 152).

De certo modo, o pesquisador passa a reconhecer que a cotidianidade é vivenciada, frequentemente, por meio da técnica. "[...] 0s meios de comunicação constituem hoje espaços-chave de condensação e intersecção de múltiplas redes de poder e de produção cultural", aponta MartínBarbero (2003, p. 20), embora ainda resista à ideia de que a tecnologia seja a grande instância mediadora entre as pessoas e 0 mundo. "[...] 0 que a tecnologia medeia hoje, de modo mais intenso e acelerado, é a transformação da sociedade em mercado, e deste em principal agenciador da mundialização (em seus muitos e contrapostos sentidos)" (MARTÍN-BARBER0, 2003, p. 20).

Para sintetizar, o pesquisador defende uma pesquisa orientada para 0 entorno dos meios, e não para seu núcleo. Para ele, cabe aos estudos de comunicação investigar o que as pessoas 
fazem a partir da recepção midiática. Apesar de sua tentativa de revisão conceitual, que passa a admitir a intensa influência da mídia sobre a cotidianidade, Martín-Barbero insiste (legitimamente) que a pesquisa comunicacional latino-americana deve privilegiar as mediações e seu caráter interdisciplinar, e não os meios.

Epistemologicamente, a nova visão do colombiano acrescenta pouco. 0 diferencial de sua obra está justamente no fato de que os códigos mediadores levantados por Martin Serrano não se fixam, necessariamente, nos meios. 0 ambiente de recepção, por exemplo, funciona como mediação ao induzir as interpretações - e o controle do cenário ou dessas mediações pode se mostrar tão sedutor quanto o comando de uma programação midiática. Um dos gargalos de sua proposta se encontra, entretanto, na definição nebulosa de mediação.

\section{Inconsistência, envelhecimento e abstracionismo: críticas à teoria}

Dos meios às mediações é um trabalho bastante denso de Martín-Barbero. Não obstante a evidência da ampla adoção do pensamento desse autor nos estudos comunicacionais da América Latina, alguns pesquisadores têm criticado sua obra e apontado fragilidades na teoria das mediações (no plural). Uma das análises mais contundentes nesse sentido vem de Luiz Signates (2006, p. 56), para quem Martín-Barbero não consegue delimitar satisfatoriamente 0 conceito de mediações, apesar da centralidade do tema em seu principal livro: "não o define claramente, nem o historia", afirma.

0 pesquisador avalia cuidadosamente $D o s$ meios às mediações e verifica que o conceito de mediação aparece 37 vezes na obra. "Dessas citações, em 21 oportunidades 0 autor 0 utiliza como categoria vinculante de dicotomias específicas e, em maioria, antinômicas [...]. Nas demais, efetua simples citações, sem um comprometimento explícito com sua definição" (SIGNATES, 2006, p. 62).

Ainda de acordo com esse estudioso, é possível extrair do livro cinco possibilidades de definição para o conceito. Seriam elas: como constructo ou categoria teórica; como discursividade específica; como estruturas, formas e práticas vinculatórias; como dispositivo de viabilização e legitimação da hegemonia ou resolução imaginária da luta de classes no âmbito da cultura; e ainda como instituição ou local geográfico. Nesse último caso, Signates (2006, p. 65) complementa: "instituição cuja prática relaciona sentidos, modos de vida e instituições (simulação e desativação dessas relações significa abandono da condição mediadora). Lugar de vivência de sentidos ambíguos ou sintetizadores (como o bairro)".

De fato, Dos meios às mediações interpõe entendimentos múltiplos para a ideia de mediação. Embora 0 laço com as questões culturais se revele profundo em todo o livro, é comum que Martín-Barbero aproxime o conceito da ideia de 
conexão (ou prática vinculatória, como prefere

Signates), mesmo quando utiliza um espaço

físico como exemplo:

0 bairro surge, então, como 0 grande mediador entre 0 universo privado da casa e 0 mundo público da cidade, um espaço que se estrutura com base em certos tipos específicos de sociabilidade e, em última análise, de comunicação: entre parentes e vizinhos. 0 bairro proporciona às pessoas algumas referências básicas para a construção de um a gente, ou seja, de uma "sociabilidade mais ampla do que aquela que se baseia nos laços familiares, e ao mesmo tempo mais densa e estável do que as relações formais e individualizadas impostas pela sociedade"5. (MARTíN-BARBER0, 2003, p. 286, grifos do autor).

Ao vincular 0 ambiente privado da casa ao universo público do restante da cidade, o bairro se apresenta como instância mediadora. Assume também a condição de espaço impreciso de vivência de sentidos. Na tentativa de amenizar os problemas com a definição do termo, Signates (2006) sugere três ideias que devem ser afastadas do entendimento de mediação: a de intermediação, a de filtro e a de intervenção no processo comunicativo ${ }^{6}$.

A crítica extrapola a obra de Martín-Barbero e atinge também pensamentos de Raymond Williams e Guillermo Orozco-Gómes. Os argumentos levantados por Signates o levam a concluir que inexiste uma teoria das mediações enquanto os estudos de comunicação não oferecerem suporte teórico-metodológico consistente. 0 autor apresenta consistência em sua fundamentação, porém exagera ao negar a existência da teoria. Martin-Barbero, inegavelmente, é vago na definição de mediação, mas tamanha radicalização pouco contribui para a construção teórica, até porque os estudiosos da obra barberiana avançaram sobremaneira no desenvolvimento conceitual.

As concepções de Martín-Barbero, Garcia Canclini e Orozco-Gómes também são alvo de contestações por parte de Marcondes Filho (2008), em artigo no qual avalia os impasses de uma teoria da comunicação latino-americana. 0 autor analisa negativamente 0 afastamento de Martín-Barbero do campo da comunicação e sua aproximação da sociologia da cultura, além de atribuir um caráter ultrapassado às ideias defendidas pelo teórico espanhol-colombiano.

0 difícil no paradigma teórico de Martín-Barbero é tentar modernizar a leitura do processo de comunicação, que exige algo novo, dinâmico, acoplado à própria dinâmica das novas tecnologias, carregando conceitos envelhecidos como ideologia, imperialismo, dominação ou hegemonia. (MARCONDES FILHO, 2008, p. 71).

A frase entre aspas é atribuída por Martín-Barbero a J. G. Cantor Magnani, autor de Festa no Pedaço, 1984, p. 138.

Para ele, assim como para Williams (1979), a ideia de intermediação está vinculada a uma visão positivista, que comprometeria 0 desenvolvimento do conceito de mediação; a noção de filtro também representaria um reducionismo teórico, pois a metáfora da filtragem significaria uma seleção de conteúdos - diferente, porém, da proposta de Martim Serrano de codificação. Por fim, 0 autor sugere cuidados ao se relacionar mediação à ideia de intervenção no processo comunicativo, pois não necessariamente esta representa uma mediação. Para mais informações, cf. SIGNATES (2006). 
Para Marcondes Filho, as conversas do entorno, aquelas que se realizam em interações posteriores ao contato com o conteúdo midiático, caracterizam um processo distinto da comunicação. Ele o denomina de prática da sociabilidade e pondera: "são momentos diferentes" (MARCONDES FILHO, 2008, p. 73). 0 autor defende que 0 fenômeno da comunicação só pode ser apreendido no instante único em que a recepção ocorre e desde que promova uma modificação interna, uma emoção, uma sensibilização no indivíduo.

Ainda de acordo com esse pesquisador, as mediações, ou seja, "tudo o que acontece depois do momento comunicacional é repercussão, é efeito, é reverberação social do fato, não mais minha experiência direta com o vivenciado" (MARCONDES FILHO, 2008, p. 77, grifo do autor). Observa-se que 0 tom da crítica envolve questões filosóficas e epistemológicas da pesquisa em comunicação, uma discussão que o próprio campo trava desde que foi instituído - ainda é vigoroso o debate sobre a instituição/ consolidação da disciplina.

As críticas de Marcondes Filho são absolutamente coerentes com a nova teoria da comunicação proposta por ele e que singulariza o momento comunicacional (MARCONDES FILHO, 2010, 2011). Em nome dessa coerência, é razoável constatar o deslocamento do epicentro da teoria barberiana em direção à sociologia - e seu afastamento da ciência da comunicação. Não cabe, no entanto, desprezar o conhecimento acumulado até então a respeito das mediações e até mesmo de outros momentos (a priori ou a posteriori) do ato comunicacional, em nome de um fechamento da concepção e sua consequente obsolescência. 0 vigor da soma e da abertura revela-se mais promissor do que a exclusão.

A teoria das mediações é classificada como demasiadamente abstrata por Cardoso Filho (2012), que aponta ainda a falta de metodologias para operacionalizá-la. De acordo com o investigador, "pesquisas recentes estão questionando metodologicamente a envergadura explicativa da teoria de MartínBarbero" (CARDOSO FILHO, 2012, p. 172), especialmente na área de estudos da recepção. A crítica é pertinente e reforçada por outros estudiosos, como Ronsini (2010), para quem é fundamental investir na pesquisa in loco da experiência, que irá delimitar o objeto e método de pesquisa. "Penso que pode ser prematuro designar a proposta de Martín-Barbero como modelo teórico-metodológico, pois se trata de uma perspectiva teórica que vem sendo desenvolvida em termos de sua especificidade no tocante à sua operacionalidade na pesquisa empírica", coloca Ronsini (2010, p. 6). De acordo com a pesquisadora, essa fragilidade é superada com a aplicação de métodos já consagrados nas ciências sociais e humanas.

A relação de críticos inclui ainda Muniz Sodré, que, adiante, terá sua obra associada 
à problemática da mediação por diversos

investigadores. Embora reconheça o indiscutível

interesse de pesquisadores do campo

comunicacional por esse tema, Sodré (2002, p. 250)

adverte que "o conceito de mediação não consegue

ultrapassar a sua enorme imprecisão cognitiva, já

apontada por vários autores, inclusive o próprio

Raymond Williams, uma de suas fontes originárias".

Diante de toda essa polêmica, esta pesquisa adota o entendimento de que a teoria das mediações carece de amadurecimento e de metodologias apropriadas que permitam operacionalizá-la. Contudo, o "dualismo básico" apontado por Williams parece superado diante da proposta de Martin Serrano, que desvincula o conceito de mediação da ideia de intermediar partes separadas. Esse viés permite compreender o funcionamento dos códigos mediadores, alavancando a percepção do modus operandi dessa teoria. Há espaço, entretanto, para aprofundar esse conhecimento e para desenvolver metodologias que ajudem a identificar e decifrar os códigos mediadores?

\section{Concepções recentes sobre as mediações sociais}

Pesquisas sobre mediações publicadas

recentemente têm procurado articular os conceitos de mediação e midiatização, conduta inevitável diante das características da sociedade contemporânea onde a recepção se concretiza. Entenda-se por midiatização o processo de reestruturação social - em vias de construção - estimulado pelo uso intensivo de tecnologias e pela adoção da lógica da mídia na condução de relacionamentos sociais. $\mathrm{Ou}$ ainda:

[...] o processo pelo qual a sociedade, em um grau cada vez maior, está submetida a ou torna-se dependente da mídia e de sua lógica. Esse processo é caracterizado por uma dualidade em que os meios de comunicação passaram a estar integrados às operações de outras instituições sociais ao mesmo tempo em que também adquiriram o status de instituições sociais em pleno direito. Como consequência, a interação social - dentro das respectivas instituições, entre instituições e na sociedade em geral - acontece através dos meios de comunicação. 0 termo lógica da mídia refere-se ao modus operandi institucional, estético e tecnológico dos meios, incluindo as maneiras pelas quais eles distribuem recursos materiais e simbólicos e funcionam com a ajuda de regras formais e informais. (HJARVARD, 2012, p. 65, grifos do autor).

0 conceito de midiatização também expõe nuances que variam de autor para autor. De Hjarvard, apreende-se que a midiatização extrapola a simples intensificação do uso de tecnologias nas interações e estabelece um novo paradigma de sociabilidade, ou, como prefere Sodré (2002), uma nova forma de vida, o bios midiático.

Na tese de doutorado citada na nota 1, foram estudados códigos mediadores do espaço físico que incidem sobre a comunicação face a face em determinados ambientes. No Pantanal brasileiro, por exemplo, a menor ocorrência de limites físicos concretos (as paisagens lá são abertas e repetitivas), a presença de animais selvagens, a abundância de água e a própria cultura dos habitantes locais direcionam os assuntos e as formas de comunicação face a face naquele espaço. Entre as metodologias utilizadas estavam a imersão e a observação participante. 
Gislene Silva (2012) enxerga similaridades

conceituais entre a vivência em um bios midiático

e as "mediações dos meios" a que se referia

Martín-Barbero. "Na contemporaneidade, é essa

'mediação social tecnologicamente exacerbada'

que, para Sodré, define-se como midiatização,

processo com relativa autonomia em face das

formas interativas presentes nas mediações

tradicionais" (SILVA, 2012, p. 115). 0 próprio

pesquisador espanhol-colombiano evoca essa

transformação ao constatar que

a mudança foi esta: reconhecer que a comunicação estava mediando todos os lados e as formas da vida cultural e social dos povos. Portanto, 0 olhar não se invertia no sentido de ir das mediações aos meios, senão da cultura à comunicação. Foi aí que comecei a repensar a noção de comunicação. (MARTíN-BARBERO, 2009a, p. 153).

As mediações, que originariamente se

concretizariam em ambientes de contato pessoal também chamados de formas de vida tradicionais - sofrem, cada vez mais, intervenções da lógica midiática, tornando indissolúvel a conexão entre mediação e midiatização. 0 bios midiático, de Sodré, apresenta-se naturalmente como o espaço contemporâneo onde se desenvolvem essas complexas relações.

Na mesma linha de pensamento, Barros (2012) busca inter-relacionar os conceitos de mediação e midiatização, lembrando que a base da teoria das mediações está em La Mediación Social, de Martin Serrano ${ }^{8}$. Ele comenta a mudança de abordagem de Martín-Barbero, destacando a força ostentada pela tecnologia nas interações humanas:

E essa reformulação nos permite traçar um paralelo entre os conceitos de mediação e midiatização. As "mediações comunicativas da cultura" poderiam ser entendidas como midiatização da cultura. Vale observar que os dois termos não são conflitantes, já que eles sugerem conotações bem próximas. Enquanto "midiatização" vem sendo pensada como uma nova forma de sociabilidade, decorrente de uma lógica midiática, "mediação" traz já de algum tempo 0 sentido das interações sociais, que nos dias de hoje se dão essencialmente - mas não exclusivamente - por intermédio da mídia. (BARROS, 2012, p. 88).

Desta forma, se a essência das relações sociais sofre alterações, os processos de mediação social - seja na perspectiva de Martin Serrano ou de Martín-Barbero - serão afetados. Tanto os códigos mediadores como as "mediações comunicativas da cultura" assumem fortemente (mas não exclusivamente) 0 viés tecnológico. Ao reconhecer que as interações ocorrem de forma preponderante (e, de novo, não exclusiva) por vias midiáticas, Barros endossa argumentos de pesquisadores que relativizam 0 conceito de midiatização, como Carvalho e Lage (2012) e Paiva (2012). Como as mediações são agora estudadas no âmbito da sociedade midiatizada 
- ou em processo de midiatização -, convém observar como se configura a apropriação da lógica midiática nas brechas visualizadas por esses autores.

Para Carvalho e Lage (2012, p. 248), "as mediações em ambiente de midiatização implicam complexos processos de negociação de sentido". 0 olhar cauteloso se justifica pelas considerações a seguir:

Partilhamos da ideia de que o processo de midiatização, a despeito de seu alicerce tecnológico e da dinâmica avassaladora com que invade os processos e mediações sociais, ainda é lacunar, pois não prepondera a ponto de suprimir formas tradicionais de sociabilidade e de atravessar com essa veemência generalizante a totalidade dos processos comunicacionais. (CARVALHO; LAGE, 2012, p. 249-250).

Em outras palavras, ainda haveria espaço na atualidade para mediações não midiatizadas, percebidas fora desse processo de reestruturação social. Os autores chegam a essa inferência ao avaliar reflexivamente os impactos da midiatização sobre 0 ambiente de produção midiática, justamente para verificar eventuais metamorfoses em mediações que envolvem o fazer jornalístico. Constatam que "as lógicas da mídia não estão imunes às demandas sociais, que as obrigam a promover mudanças nos seus modos e formas de dar a ver as sociedades em suas contradições" (CARVALHO; LAGE, 2012, p. 250-251).

Como exemplo, eles apontam que o processo de produção jornalística tem incrementado a participação do público receptor, seja por meio do estímulo ao "eu repórter", seja pela invasão das imagens de procedência amadora, entre outras. Esse fenômeno, inerente ao processo de midiatização, provoca um rearranjo de papéis na prática cotidiana do jornalismo, porém, é insuficiente para modificar sua essência. "Mesmo que com novos participantes, a produção jornalística ainda é submissa a parâmetros e constrangimentos organizacionais. Daí porque seria equivocado superestimar o 'protagonismo do leitor' [...]", acrescentam Carvalho e Lage (2012, p. 255). A conclusão do estudo atesta que, embora os sistemas tecnológicos e as formas de interação sejam moldados pela midiatização, os processos comunicacionais que permitem construir a realidade ainda são organizados e definidos pela sociedade. "A midiatização não inaugura um ambiente de convergência, mas garante a entrada de novos dispositivos, novos agentes, instaurando novas formas de mediação", apontam Carvalho e Lage (2012, p. 256-257), interligando os dois conceitos e negando 0 caráter absolutista da midiatização.

Outro pesquisador que relativiza o fenômeno da midiatização é Paiva (2012, p. 149), ao lembrar que "do lado de fora da sociedade midiatizada estão os desplugados, os 'sem banda larga', os outsiders do século XXI". Essa categoria, ainda desconectada, provavelmente vivencia os processos de midiatização e de mediação de modo diferenciado. Esses indivíduos estariam excluídos da nova ordem da cultura se for 
considerado válido o "imperativo da visibilidade", comprometendo efeitos generalizantes da midiatização.

Na perspectiva germânica, a ideia de mediação apresenta uma abordagem mais abstrata que na América Latina, de acordo com Bastos (2012). 0 conceito estaria descolado das noções de media e de comunicação, "pois seu objeto é a circulação social dos signos na cultura" (BASTOS, 2012, p. 65). Na perspectiva desse pesquisador, estudos alemães inserem a mediação como uma etapa inicial do processo de midiatização, que se manifesta sempre que os veículos de comunicação de massa se transformam em fonte principal de informação em determinado recorte social. Esse processo avança na medida em que as audiências vão se tornando dependentes da mídia.

Com isso, 0 entendimento das mediações praticado na América Latina, que remete a processos de negociação de significado e sentido entre produtores e consumidores de media, ou à maneira como temas e debates são reconfigurados após circularem nos meios de comunicação, é objeto de controvérsia em outros contextos acadêmicos. (BASTOS, 2012, p. 71)..$^{10}$

Outra concepção relativamente recente de mediação é apresentada por Sodré (2002, 2006), que comumente vincula o conceito a instituições sociais, como família, escola, igreja, sindicato, partido, entre outras. Conforme esse pensador, as mediações estão condicionadas a bases materiais, "que se consubstanciam em instituições ou formas reguladoras do relacionamento em sociedade" (SODRÉ, 2002, p. 21). Essas instituições acabam por orientar práticas de conduta que mobilizam as consciências individuais e coletivas. "Valores e normas institucionalizados legitimam e outorgam sentido social às mediações", acrescenta Sodré (2002, p. 21). Quatro anos depois, o pesquisador arrisca uma definição mais direta:

\section{Mediação é 0 ato originário de qualquer cogni- ção, porque implica o trânsito ou a "comunica- ção" da propriedade de um elemento para outro, por meio de um terceiro termo. Este terceiro é precisamente o signo, um meio de articular dois elementos diversos, por exemplo, um objeto e uma ideia interpretante. (SODRÉ, 2006, p. 91).}

A noção de prática vinculatória de Martín-Barbero está presente no conceito proposto por Sodré, embora não o restrinja. Ao relacionar mediações a instituições reguladoras dos relacionamentos sociais, o pesquisador brasileiro sugere uma articulação que estabelece sentidos apriorísticos para determinadas interações. Diante do bios midiático, em que as relações entre sujeito e instituições se virtualizam, as mediações, também na concepção de Sodré, tendem a sofrer profundas alterações.

Conceito atribuído à pesquisadora argentina Paula Sibilia, que significa a necessidade de exposição pessoal na sociedade contemporânea, na linha de que, para "existir", é necessário "ser visto" na internet.

10 Bastos chega a essa conclusão após avaliar o artigo supracitado de Livingstone (2009), que apresenta diferentes significados para o termo mediação em decorrência do idioma escolhido. 
A pesquisa em comunicação - e em midiatização

- assume riscos metodológicos se optar pela expansão indiscriminada da noção de mediação para quaisquer instâncias. Signates (2006, p. 76) alerta para a tendência inquietante de se considerar tudo como mediação:

\begin{abstract}
Afinal, se a noção de mediação se tornar um conceito do tipo guarda-chuva, que permita levar até a mais simplória das totalizações - tudo é mediação (logo, nada o é) - todo o valor heurístico propiciado pela abertura de suas possibilidades pode redundar apenas em generalizações sem qualquer utilidade teórica.
\end{abstract}

0 apelo final de Signates alerta para o risco do uso indevido do termo mediação sem as devidas contextualizações e fundamentações. Por mais que a definição permaneça sombreada e que pairem dúvidas em relação às diferentes perspectivas a serem assumidas, é necessária cautela na aplicação do conceito. É recomendável, sempre que possível, orientar a leitura para que a noção de mediação seja associada ao entendimento desejado - ao menos enquanto a discussão sobre ela não se aproxime de um consenso.

\section{Considerações finais}

Depois de problematizar a teoria das mediações, este artigo passa a considerar as seguintes perspectivas: a) as relações sociais são permeadas por códigos mediadores que orientam interpretações e que são instaurados pela instância mediadora como forma de controle social; b) esses códigos não são exclusivos dos meios de comunicação, embora essa fonte de mediação se fortaleça na sociedade midiatizada; c) nem sempre os códigos mediadores estão explícitos e há carência de metodologias para sua identificação; d) mediação e midiatização são fenômenos interdependentes; e) é reconhecível o processo de dependência dos relacionamentos sociais em relação à lógica da mídia, porém, 0 mesmo deve ser relativizado; e f) as críticas à teoria das mediações não inviabilizam a continuidade das pesquisas para ampliar o conhecimento a respeito desse fenômeno; pelo contrário, são elas que lapidam e direcionam esse saber.

As diferentes concepções de mediação aqui estudadas podem, em certa medida, compor uma definição menos nebulosa do que a apresentada, por exemplo, por Martín-Barbero. Conforme demonstrado, há pontos de confluência e complementaridade entre os pensamentos que formatam a teoria. Esta pesquisa aponta que a perspectiva de Martin Serrano tem potencial para servir de base para estudos posteriores, especialmente por superar de modo aceitável 0 impasse colocado por Williams.

Este estudo procurou contribuir com a construção conceitual e indica a necessidade de se conduzir pesquisas que deflagrem trajetos metodológicos. Pode-se inferir que as mediações sociais são cada vez mais condicionadas pelo fenômeno da midiatização, embora em alguns redutos esse processo ocorra de forma menos invasiva, dependendo de condições de acesso 
à tecnologia, variáveis culturais e até mesmo posicionamento geográfico.

Apesar da fragilidade metodológica e do distanciamento do campo da comunicação, conforme perspectiva de Marcondes Filho (2008), é patente que 0 saber proporcionado pela teoria das mediações sociais reúne arcabouço suficiente para delinear pesquisas e esclarecer comportamentos e dinâmicas sociais - fundamentais para a compreensão de processos comunicacionais. Críticas construtivas são imprescindíveis para 0 aprimoramento do conhecimento científico. Quaisquer correntes teóricas são suscetíveis de restaurações e refinamentos - processos em pleno vigor no caso aqui estudado.

\section{Referências}

BARROS, Laan Mendes de. Os meios ou as mediações? Um exercício dialético na delimitação do objeto de estudo da comunicação. Líbero, São Paulo, v. 12, nº 23, p. 85-94, jun. 2009. Disponível em: http://casperlibero. edu.br/wp-content/uploads/2014/05/0s-meios-ou-asmedia\%C3\%A7\%C3\%B5es1.pdf. Acesso em: 2 jul. 2015.

. Recepção, mediação e midiatização: conexões

entre teorias europeias e latino-americanas. In: MATTOS, Maria Ângela; JANOTTI JR., Jeder; JACKS, Nilda (Orgs.). Mediação \& midiatização. Salvador: EDUFBA; Brasília: Compós, 2012. p. 79-105.

BASTOS, Marco Toledo. Medium, media, mediação e midiatização: a perspectiva germânica. In: MATTOS, Maria Ângela; JANOTTI JR., Jeder; JACKS, Nilda (Orgs.). Mediação \& midiatização. Salvador: EDUFBA; Brasília: Compós, 2012. p. 53-77.

CARDOSO FILHO, Jorge Luiz Cunha. Inflexões metodológicas para a teoria do uso social dos meios e processos de midiatização. In: MATTOS, Maria Ângela; JANOTTI JR., Jeder; JACKS, Nilda (Orgs.). Mediação

\& midiatização. Salvador: EDUFBA; Brasília: Compós, 2012. p. 171-191.

CARVALHO, Carlos Alberto de; LAGE, Leandro. Midiatização e reflexividade das mediações jornalísticas. In: MATTOS, Maria Ângela; JANOTTI JR., Jeder; JACKS, Nilda (Orgs.). Mediação \& midiatização. Salvador: EDUFBA; Brasília: Compós, 2012. p. 245-269.

HJARVARD, Stig. Midiatização: teorizando a mídia como agente de mudança social e cultural. Matrizes, São Paulo, ano 5, no 2, p. 53-91, jan./jun. 2012.

Disponível em: http://www.matrizes.usp.br/index.php/ matrizes/article/view/338/pdf. Acesso em: 21 abr. 2015.

LIVINGSTONE, Sonia. On the mediation of everything: ICA presidential address 2008. Journal of Communication, Washington, v. 59, n. 1, p. 1-18, mar. 2009. Disponível em: http://eprints.lse.ac.uk/21420/1/ On_the_mediation_of_everything_\%28LSER0\%29.pdf. Acesso em: 30 mar. 2014.

MALDONAD0, Alberto Efendy. Confluências epistemológicas: teoria da mediação social de Martín Serrano e pensamento crítico transformador latinoamericano. Eptic 0n Line, São Cristóvão, v. 10, nº 3, set./dez. 2008. Disponível em: http://www.seer.ufs.br/ index.php/eptic/article/viewFile/195/166. Acesso em: 2 ago. 2014.

MARCONDES FILHO, Ciro. Martín-Barbero, Canclini e Orozco. Os impasses de uma teoria da comunicação latino-americana. Famecos, Porto Alegre, v. 1, nº 35, p. 69-85, abr. 2008.

0 princípio da razão durante: 0 conceito de comunicação e a epistemologia metapórica: nova teoria da comunicação III: tomo V. São Paulo: Paulus: 2010.

0 princípio da razão durante: 0 círculo cibernético: o observador e a subjetividade: nova teoria da comunicação III: tomo III. São Paulo: Paulus, 2011. 
MARTIN SERRANO, Manuel: Mediación. In: DEL CAMPO, Salustiano (Org.). Diccionario de ciencias sociales. Madrid: Instituto de Estudios Políticos/ Unesco, p. 179-184, 1976. Disponível em: http://eprints. ucm.es/10657/. Acesso em: 3 ago. 2014.

Prólogo para A mediação social na era da globalização. Mediaciones Sociales, Madri, $n^{0} 1, p$. 1-26, $2^{0}$ sem. 2007. Disponível em: http://www.ucm. es/info/mediars/MediacioneS1/Indice/MartinSerrano/ martinserrano.html. Acesso em: 4 ago. 2014.

La estructura de la narración icónica en la televisión. Disertación magistral de Doctorado de Estado en Ciencias y Letras. Razón y Palabra, México, n. 72, p. 1-17, jul. 2010. Disponível em: http://www. razonypalabra.org.mx/N/N72/MMS/MMS_castellano_ corr_72.pdf. Acesso em: 26 jun. 2015.

MARTÍN-BARBERO, Jesús. Comunicação e mediações culturais. Entrevistador: Claudia Barcelos. Revista Brasileira de Ciências da Comunicação, São Paulo, v. 23, n. 1, p. 151-163, jan./jun. 2000. Disponível em: http://www. portcom.intercom.org.br/revistas/index.php/revistaintercom/ article/view/541/510. Acesso em: 26 nov. 2013.

Dos meios às mediações: comunicação, cultura e hegemonia. $2^{\mathrm{a}}$ ed. Rio de Janeiro: Editora UFRJ, 2003.

. Uma aventura epistemológica. Entrevistador: Maria Immacolata Vassallo de Lopes. Matrizes, São Paulo, v. 2, no 2, p. 143-162, jan./jun. 2009a. Disponível em: http://www.matrizes.usp.br/index.php/matrizes/ article/view/111/178. Acesso em: 3 ago. 2014.

. As formas mestiças da mídia. Entrevistador: Mariluce Moura. Pesquisa Fapesp, São Paulo, $n^{0} 163$, p. 10-15, set. 2009b. Disponível em: http://revistapesquisa.fapesp.br/wp-content/ uploads/2009/09/010-015_entrevista_163.pdf?551641. Acesso em: 27 jul. 2015.

MARTINO, Luís Mauro Sá. Teoria da comunicação: ideias, conceitos e métodos. Petrópolis: Vozes, 2009.
MATE, Esteban. Reseña de La mediación social. Anthropos, Logroño, n. 41-42, p. 74-75, 1984. Disponível em: http://eprints.ucm.es/10657/1/Martin_ Serrano_\%281976\%29_Mediacion.pdf. Acesso em: 4 ago. 2014 .

PAIVA, Cláudio Cardoso de. Sob o signo de Hermes, o espírito mediador: midiatização, interação e comunicação compartilhada. In: MATTOS, Maria Ângela; JANOTTI JR., Jeder; JACKS, Nilda (Orgs.).

Mediação \& midiatização. Salvador: EDUFBA; Brasília: Compós, 2012. p. 149-170.

RONSINI, Veneza V. Mayora. A perspectiva das mediações de Jesús Martín-Barbero (ou como sujar as mãos na cozinha da pesquisa empírica de recepção). In: XIX ENCONTRO ANUAL DA COMPÓS, 2010. Rio de Janeiro. Anais eletrônicos... Rio de Janeiro: PUC, 2010. Disponível em: http://compos.com.puc-rio.br/ media/gt12_veneza_ronsini.pdf. Acesso em: 2 jul. 2015.

SIGNATES, Luiz. Estudo sobre o conceito de mediação e sua validade como categoria de análise para os estudos de comunicação. In: Sousa, Mauro Wilton de (Org.). Recepção mediática e espaço público: novos olhares. São Paulo: Paulinas, 2006. p. 55-79.

SILVA, Gislene. Pode o conceito reformulado de bios midiático conciliar mediações e midiatização? In: MATTOS, Maria Ângela; JANOTTI JR., Jeder; JACKS, Nilda (Orgs.). Mediação \& midiatização. Salvador: EDUFBA; Brasília: Compós, 2012. p. 107-122.

SODRÉ, Muniz. Antropológica do espelho: uma teoria da comunicação linear e em rede. Petrópolis: Vozes, 2002.

As estratégias sensíveis: afeto, mídia e política. Petrópolis: Vozes, 2006.

THOMPSON, John B. A mídia e a modernidade: uma teoria social da mídia. 9ª ed. Petrópolis: Vozes, 2008.

Ideologia e cultura moderna: teoria social crítica na era dos meios de comunicação de massa. 9. ed. Petrópolis: Vozes, 2011. 
WILLIAMS, Raymond. Marxismo e literatura.

Tradução Waltensir Dutra. Rio de Janeiro: Zahar

Editores, 1979. Disponível em: https://www.

passeidireto.com/arquivo/10901474/marxismo-

e-literatura---williams-raymond/2. Acesso em: 22

jul. 2016. 


\begin{tabular}{|c|c|}
\hline $\begin{array}{l}\text { Theory of social mediations: } \\
\text { refinement or obsolescence? }\end{array}$ & $\begin{array}{l}\text { Teoria de las mediaciones sociales: } \\
\text { sofisticación u obsolescencia? }\end{array}$ \\
\hline $\begin{array}{l}\text { Abstract } \\
\text { The article proposes a plunge into the origins and } \\
\text { recent concepts of the theory of social mediations, } \\
\text { providing reflections on their applicability. It } \\
\text { points to methodological weaknesses and redeems } \\
\text { conceptual criticisms based on the departure of } \\
\text { theory from the field of communications. It relates } \\
\text { current research on mediations to the concept of } \\
\text { mediatizaton, a trend followed by Brazilian and } \\
\text { foreign researchers. Through literature review, } \\
\text { we conclude that the theory is in permanent } \\
\text { construction and is potentially able to respond to } \\
\text { some communication questions. } \\
\text { Keywords } \\
\text { Mediations. Mediatization. Mass media. Media bios. }\end{array}$ & $\begin{array}{l}\text { Resumen } \\
\text { El artículo propone una inmersión en los orígenes } \\
\text { y los últimos conceptos de la teoría de las } \\
\text { mediaciones sociales, proporcionando reflexiones } \\
\text { sobre su aplicabilidad. Puntea debilidades } \\
\text { metodológicas y rescata la crítica conceptual } \\
\text { basada en el aislamiento de la teoría del campo de la } \\
\text { comunicación. A la vez, relaciona la investigación } \\
\text { actual acerca de las mediaciones al concepto } \\
\text { de mediatización, una tendencia seguida por } \\
\text { investigadores brasileños y extranjeros. A través } \\
\text { de una investigación bibliográfica, se concluye } \\
\text { que la teoria está en construcción permanente } \\
\text { y, potencialmente, puede responder a algunas } \\
\text { preguntas relacionadas a la Comunicación. } \\
\text { Palabras clave } \\
\text { Mediaciones. Mediatización. Medios de } \\
\text { comunicación. Bios midiático. }\end{array}$ \\
\hline
\end{tabular}




\section{Expediente}

A revista E-Compós é a publicação científica em formato eletrônico da Associação Nacional dos Programas de Pós-Graduação em Comunicação (Compós). Lançada em 2004, tem como principal finalidade difundir a produção acadêmica de pesquisadores da área de Comunicação, inseridos em instituições do Brasil e do exterior.

\section{E-COMPÓS I www.e-compos.org.br I E-ISSN 1808-2599}

Revista da Associação Nacional dos Programas de Pós-Graduação em Comunicação.

Brasília, v.19, n.3, set./dez. 2016.

A identificação das edições, a partir de 2008, passa a ser volume anual com três números.

Indexada por Latindex I www.latindex.unam.mx

\section{CONSELHO EDITORIAL}

Alexandre Farbiarz, Universidade Federal Fluminense, Brasil Alexandre Rocha da Silva, Universidade Federal do Rio Grande do Sul, Brasil Ana Carolina Escosteguy, Pontifícia Universidade Católica do Rio Grande do Sul, Brasil Ana Carolina Rocha Pessôa Temer, Universidade Federal de Goiás, Brasil Ana Regina Barros Rego Leal, Universidade Federal do Piauí, Brasil Andrea França, Pontifícia Universidade Católica do Rio de Janeiro, Brasil André Luiz Martins Lemos, Universidade Federal da Bahia, Brasil Antonio Carlos Hohlfeldt, Pontifícia Universidade Católica do Rio Grande do Sul, Brasil Arthur Ituassu, Pontifícia Universidade Católica do Rio de Janeiro, Brasil Álvaro Larangeira, Universidade Tuiuti do Paraná, Brasil Ângela Freire Prysthon, Universidade Federal de Pernambuco, Brasil César Geraldo Guimarães, Universidade Federal de Minas Gerais, Brasil Cláudio Novaes Pinto Coelho, Faculdade Cásper Líbero, Brasil Daisi Irmgard Vogel, Universidade Federal de Santa Catarina, Brasil Denize Correa Araujo, Universidade Tuiuti do Paraná, Brasil

Eduardo Antonio de Jesus, Pontifícia Universidade Católica de Minas Gerais, Brasil Daniela Zanetti, Universidade Federal do Espirito Santo, Brasil

Eduardo Vicente, Universidade de São Paulo, Brasil

Elizabeth Moraes Gonçalves, Universidade Metodista de São Paulo, Brasil Erick Felinto de Oliveira, Universidade do Estado do Rio de Janeiro, Brasil Francisco Elinaldo Teixeira, Universidade Estadual de Campinas, Brasil Francisco Paulo Jamil Almeida Marques, Universidade Federal do Paraná, Brasil Gabriela Reinaldo, Universidade Federal do Ceará, Brasil

Goiamérico Felício Carneiro Santos, Universidade Federal de Goiás, Brasil Gustavo Daudt Fischer, Universidade do Vale do Rio dos Sinos, Brasil Herom Vargas, Universidade Municipal de São Caetano do Sul, Brasil Itania Maria Mota Gomes, Universidade Federal da Bahia, Brasil Janice Caiafa, Universidade Federal do Rio de Janeiro, Brasil Jiani Adriana Bonin, Universidade do Vale do Rio dos Sinos, Brasil
José Afonso da Silva Junior, Universidade Federal de Pernambuco, Brasil José Luiz Aidar Prado, Pontifícia Universidade Católica de São Paulo, Brasil Juçara Gorski Brittes, Universidade Federal de Ouro Preto, Brasil Kati Caetano, Universidade Tuiuti do Paraná, Brasil Lilian Cristina Monteiro França, Universidade Federal de Sergipe, Brasil Liziane Soares Guazina, Universidade de Brasilia, Brasil Luíza Mônica Assis da Silva, Universidade de Caxias do Sul, Brasil Luciana Miranda Costa, Universidade Federal do Pará, Brasil Malena Segura Contrera, Universidade Paulista, Brasil Monica Martinez, Universidade de Sorocaba, Brasi Maria Ataide Malcher, Universidade Federal do Pará, Brasil Marcia Tondato, Escola Superior de Propaganda e Marketing, Brasil Marcel Vieira Barreto Silva, Universidade Federal da Paraíba, Brasil Maria Clotilde Perez Rodrigues, Universidade de São Paulo, Brasil Maria das Graças Pinto Coelho, Universidade Federal do Rio Grande do Norte, Brasil Mauricio Ribeiro da Silva, Universidade Paulista, Brasil

Mauro de Souza Ventura, Universidade Estadual Paulista, Brasil Márcio Souza Gonçalves, Universidade do Estado do Rio de Janeiro, Brasil Micael Maiolino Herschmann, Universidade Federal do Rio de Janeiro, Brasil Mirna Feitoza Pereira, Universidade Federal do Amazonas, Brasil Nísia Martins Rosario, Universidade Federal do Rio Grande do Sul, Brasil Potiguara Mendes Silveira Jr, Universidade Federal de Juiz de Fora, Brasil Regiane Regina Ribeiro, Universidade Federal do Paraná, Brasil Rogério Ferraraz, Universidade Anhembi Morumbi, Brasil Rose Melo Rocha, Escola Superior de Propaganda e Marketing, Brasil Rozinaldo Antonio Miani, Universidade Estadual de Londrina, Brasil Sérgio Luiz Gadini, Universidade Estadual de Ponta Grossa, Brasil Simone Maria Andrade Pereira de Sá, Universidade Federal Fluminense, Brasil Veneza Mayora Ronsini, Universidade Federal de Santa Maria, Brasil Walmir Albuquerque Barbosa, Universidade Federal do Amazonas, Brasil

\section{CONSELHO CIENTÍFICO}

Cristiane Freitas Guttreind, Pontifícia Universidade Católica do Rio Grande do Sul, Brasil Eduardo Morettin, Universidade de São Paulo, Brasil Felipe Costa Trotta, Universidade Federal Fluminense, Brasil Irene de Araújo Machado, Universidade de São Paulo, Brasil

\section{COMISSÃO EDITORIAL}

Eduardo Antonio de Jesus, Pontifícia Universidade Católica de Minas Gerais, Brasil Osmar Gonçalves dos Reis Filho, Universidade Federal do Ceará, Brasil

\section{CONSULTORES AD HOC}

Geane C. Alzamora, Universidade Federal de Minas Gerais, Brasil Teresinha Cruz Pires, Pontifícia Universidade Católica de Minas Gerais, Brasil

\section{EQUIPE TÉCNICA}

ASSISTENTE EDITORIAL Márcio Zanetti Negrini

REVISÃO DE TEXTOS Press Revisão

EDITORAÇÃO ELETRÔNICA Roka Estúdio

IMAGEM DE CAPA Silas de Paula

\section{COMPÓS I www.compos.org.br}

Associação Nacional dos Programas de Pós-Graduação em Comunicação

Presidente

Edson Fernando Dalmonte

Programa de Pós-Graduação em Comunicação

e Cultura Contemporânea - UFBA

edsondalmonte@uol.com.br

Vice-presidente

Cristiane Freitas Gutfreind

Programa de Pós-Graduação em Comunicação Social - PUC-RS cristianefreitas@pucrs.br

Secretário-Geral

Rogério Ferraraz

Programa de Pós-Graduação em Comunicação

Universidade Anhembi Morumbi

rogerioferraraz@anhembimorumbi.edu.br

CONTATO I revistaecompos@gmail.com 